\title{
Hubungan Pengetahuan dan Sikap terhadap Perilaku Penggunaan Alat Pelindung Diri di PT Sarandi Karya Nugraha Sukabumi
}

\author{
Livia Assyifa Rachman, ${ }^{1}$ Fajar Awalia Yulianto, ${ }^{2}$ Ahmad Djojosugito, ${ }^{3}$ \\ Mia Yasmina Andarini, ${ }^{4}$ Tony S. Djajakusumah ${ }^{4}$ \\ ${ }^{1}$ Program Studi Pendidikan Dokter, ${ }^{2}$ Bagian Ilmu Kesehatan Masyarakat, \\ ${ }^{3}$ Bagian Bedah Orthopedi, ${ }^{4}$ Bagian Ilmu Kesehatan Kulit dan Kelamin \\ Fakultas Kedokteran Universitas Islam Bandung,
}

\begin{abstract}
Abstrak
Berdasar atas data International Labour Organization (ILO) tahun 2013, satu pekerja di dunia meninggal disebabkan oleh kecelakaan kerja dan 160 pekerja mengalami sakit akibat kerja setiap 15 detik. Tujuan penelitian ini adalah melihat karakteristik usia, dan pengetahuan serta hubungan pengetahuan, sikap, lingkungan, pendapatan dan pendidikan dengan perilaku penggunaan alat pelindung diri di PT Sarandi Karya Nugraha Sukabumi. Metode penelitian adalah observasional analitik dengan pendekatan cross sectional. Sampel penelitian adalah karyawan PT Sarandi Karya Nugraha Sukabumi yang bekerja di bagian gudang dan processing $(\mathrm{n}=80)$ yang diambil secara simple random sampling periode Maret-Mei 2018. Instrumen yang digunakan adalah kuesioner. Hasil penelitian menunjukkan bahwa usia responden paling banyak adalah dewasa awal (18-40 tahun). Responden juga memiliki tingkat pengetahuan yang tinggi terhadap APD. Tidak ada hubungan pengetahuan $(p=0,17)$, sikap $(p=0,84)$, pendapatan $(\mathrm{p}=0,27)$, lingkungan $(\mathrm{p}=0,61)$, dan pendidikan $(\mathrm{p}=1,00)$ dengan perilaku penggunaan alat pelindung diri di PT Sarandi Karya Nugraha Sukabumi.
\end{abstract}

Kata kunci: Pengetahuan, penggunaan APD, sikap

\section{Relationship between Knowledge and Attitude with Behavior of Using Personal Protecticve Equipment in PT Sarandi Karya Nugraha Sukabumi}

\begin{abstract}
Based on the 2013 data from the International Labour Organization (ILO), one worker dies due to workplace accidents and 160 workers suffer from work-related injuries every 15 seconds worldwide. The purpose of this study was to determine the characteristic of age and knowledge and the relationship between knowledge, attitude, environment, income, education with behavior of using personal protective equipment in PT Sarandi Karya Nugraha Sukabumi. The study was analytic observational study with cross sectional approach during March-April 2018. The sample was the employee of PT Sarandi Karya Nugraha who worked in processing department $(n=80)$ with simple random sampling. The instrument of this study was questionnaire. The result of the study was most respondents were early adult (18-40 years old). Respondents had a good knowledge and there was no relationship between knowledge $(\mathrm{p}=0.17)$, attitude $(\mathrm{p}=0.84)$, income $(\mathrm{p}=0.27)$, environment $(\mathrm{p}=\mathrm{o} .61)$, education $(\mathrm{p}=1.00)$ with behavior of using personal protective equipment in PT Sarandi Karya Nugraha Sukabumi
\end{abstract}

Keywords: Attitude, behavior using personal productive equipment, knowledge

Received: 8 January 2020; Revised: 25 July 2020; Accepted: 30 July 2020; Published: 31 July 2020

Koresponden: Livia Assyifa Rachman. Program Pendidikan Studi Kedokteran, Fakultas Kedokteran, Universitas Islam Bandung, Jl. Tamansari No. 22, Kota Bandung, Provinsi Jawa Barat. Telepon (022) 4203368 


\section{Pendahuluan}

Era global ditandai dengan 'menipisnya' batas antarnegara yang akan menimbulkan perubahan yang cepat di segala bidang dan dapat berdampak positif dan negatif. Dalam bidang kesehatan dan keselamatan kerja $\left(\mathrm{K}_{3}\right)$ positifnya adalah dapat dengan mudah mengakses informasi dari negara yang industrinya sudah maju. Dampak negatifnya adanya ketidaksiapan untuk mengantisipasi hambatan dalam persaingan global yang dapat menyebabkan penyakit akibat kerja atau kecelakaan kerja. ${ }^{1}$

Berdasar atas data dari International Labour Organization (ILO) tahun 2013, satu pekerja di dunia meninggal disebabkan oleh kecelakaan kerja dan 160 pekerja mengalami sakit akibat kerja setiap 15 detik. $^{2}$ Di Indonesia menurut Direktorat Bina Kerja dan Olahraga, Kementrian Kesehatan, 2014, jumlah kasus kecelakaan akibat kerja tahun 2011-2014 paling tinggi pada tahun 2013 yaitu 35.917 kasus kecelakaan kerja. Jumlah kasus penyakit akibat kerja tahun 2011-2014 terjadi penurunan (tahun 2011=57.929; tahun 2012= 60.322; tahun $2014=40.696$ ). Provinsi dengan jumlah kasus penyakit akibat kerja tertinggi pada tahun tahun 2012 adalah Provinsi Sumatera Utara, Sumatera Selatan, dan Jawa Barat. ${ }^{3}$

Penggunaan alat pelindung diri telah diatur dalam UU No. 1 Tahun 1970 tentang Keselamatan Kerja dan PER.08/MEN/VII/2010 tentang Alat Pelindung Diri. ${ }^{4}$ Sepuluh industri prioritas nasional menurut Kementrian Industri salah satunya adalah industri yang bergerak di bidang alat kesehatan dan industri alat kesehatan masuk kedalam industri andalan. PT Sarandi Karya Nugraha adalah perusahaan yang telah menerapkan manjemen mutu. Hal ini yang mendasari peneliti untuk melakukan penelitian ini.

Berdasaratashaltersebutmakapenelitian bertujuan mengetahui hubungan pengetahuan dengan perilaku penggunaan alat pelindung diri di PT Sarandi Karya Nugraha dan untuk mengetahui hubungan antara sikap dan perilaku penggunaan alat pelindung diri di PT Sarandi Karya Nugraha Sukabumi.

\section{Metode}

Penelitian ini menggunakan rancangan penelitian dengan metode deskriptif dengan desain studi cross sectional. Teknik pengambilan data menggunakan survei kepada 210 responden dengan teknik pemilihan purposive sampling. Data yang digunakan adalah data primer yang diambil dari kuesioner yang disebarkan di Desa Pangalengan Kecamatan Pangalengan Kabupaten Bandung.

Penelitian ini dilakukan pada bulan Maret 2020 untuk mengetahui perbandingan gambaran BMI dengan tekanan darah pada penderita tuberkulosis dan non tuberkulosis di Desa Pangalengan Tahun 2020 dengan subjek penelitian 210 responden. Instrumen penelitian adalah kuosioner dengan variabel menilai BMI dan tekanan darah terhadap kejadian TB paru di Desa Pangalengan dengan cara mengukur berat badan, tinggi badan, serta tekanan darah pada pasien tuberkulosis dan non tuberkulosis.

\section{Hasil}

Penelitian telah dilakukan di PT Sarandi Karya Nugraha Sukabumi pada bulan Maret-Mei 2018 dengan subjek penelitian karyawan PT Sarandi Karya Nugraha Sukabumi yang bekerja di bagian gudang dan processing, yang bersedia menjadi responden dan memenuhi kriteria inklusi.

Tabel 1 Skor Pengetahuan Mengenai Alat Pelindung Diri

\begin{tabular}{lcc}
\hline \multicolumn{1}{c}{ Pertanyaan } & Benar & Salah \\
\cline { 2 - 3 } & $\mathbf{n}$ & $\mathbf{n}$ \\
\hline $\begin{array}{l}\text { Apakah anda tahu tentang alat pelindung } \\
\text { diri? }\end{array}$ & 80 & 0 \\
$\begin{array}{l}\text { Apakah alat pelindung diri meliputi } \\
\text { pakaian kerja, penutup kepala, alat } \\
\text { pelindung pernapasan, alat pelindung } \\
\text { mata, alat pelindung kaki? }\end{array}$ & 69 & 11 \\
$\begin{array}{l}\text { Apakah salah satu syarat alat pelindung } \\
\text { diri harus terbuat dari bahan yang tidak } \\
\text { menimbulkan bahaya? }\end{array}$ & 78 & 2 \\
$\begin{array}{l}\text { Apakah dalam bekerja perlu } \\
\text { menggunakan alat pelindung diri? }\end{array}$ & 79 & \\
$\begin{array}{l}\text { Apakah alat pelindung diri yang baik } \\
\text { adalah alat pelindung yang tidak } \\
\text { mengganggu saat di pakai bekerja? }\end{array}$ & 75 & 5 \\
$\begin{array}{l}\text { Apakah bahan kimia dapat menyebabkan } \\
\text { penyakit akibat kerja seperti kemerahan } \\
\text { pada kulit, panyakit saluran pernapasan? }\end{array}$ & 76 & 4 \\
$\begin{array}{l}\text { Apakah syarat alat pelindung diri adalah } \\
\text { tidak menggagu kenyamanan kerja? }\end{array}$ & 68 & 12 \\
$\begin{array}{l}\text { Apakah anda tahu bahaya yang } \\
\text { ditimbulkan dari bahan kimia di tempat } \\
\text { kerja? }\end{array}$ & 73 & 7 \\
$\begin{array}{l}\text { Apakah anda tahu tujuan dari } \\
\text { penggunaan alat pelindung diri? }\end{array}$ & 89 & 1 \\
\hline
\end{tabular}

Pada tabel 1 terlihat bahwa sebagian besar responden memiliki pengetahuan yang baik mengenai APD, yang dapat dilihat melalui skor benar pertanyaan.

Tabel 2 Skor Pengetahuan Mengenai Alat Pelindung Diri

\begin{tabular}{lccccc}
\hline $\begin{array}{c}\text { Skor } \\
\text { Pengetahuan }\end{array}$ & Median & Min. & Maks. & $\begin{array}{c}\text { Mean } \\
\text { (\%) }\end{array}$ & SD \\
\hline Benar & 100 & 55,56 & 100 & 93,79 & 9,45 \\
& & & & & \\
\hline
\end{tabular}

Berdasar atas Tabel 2 didapatkan hasil rerata skor pengetahuan mengenai alat pelindung diri adalah 93,79\%. 
Tabel 3 Kategori Usia

\begin{tabular}{ll}
\hline Kategori Usia (Tahun) & n \\
\hline Dewasa awal (18-41) & 72 \\
Dewasa lanjut (41-60) & 8 \\
\hline
\end{tabular}

Berdasar atas Tabel 3 mayoritas responden adalah usia dewasa awal

\begin{tabular}{|c|c|c|c|c|}
\hline Tabel 4 & \multicolumn{3}{|c|}{$\begin{array}{l}\text { Hubungan Pend } \\
\text { Penggunaan APD }\end{array}$} & dan \\
\hline \multirow{2}{*}{ Pendapatan } & \multicolumn{2}{|c|}{ Penggunaan APD } & \multirow{2}{*}{ Total } & \multirow{2}{*}{$\mathbf{p}$} \\
\hline & Buruk & Baik & & \\
\hline UMK & 16 & 43 & 59 & \multirow{2}{*}{0,27} \\
\hline > UMK & 5 & 16 & 21 & \\
\hline
\end{tabular}

Tabel 4 menunjukkan bahwa tidak ada hubungan antara pendapatan dengan penggunaan APD $(p=0,27)$

Tabel 5 Hubungan Sikap dan Penggunaan APD

\begin{tabular}{lcccc}
\hline \multirow{2}{*}{ Sikap } & \multicolumn{2}{c}{ Penggunaan APD } & Total & p \\
\cline { 2 - 3 } & Buruk & Baik & & \\
\hline Buruk & 6 & 28 & 34 & 0,84 \\
Baik & 9 & 37 & 46 & \\
\hline
\end{tabular}

Tabel 5 menunjukkan bahwa tidak ada hubungan antara sikap dan penggunaan APD karena didapatkan nilai $\mathrm{p}=0,84$

\begin{tabular}{|c|c|c|c|c|}
\hline $\begin{array}{cc}\text { Tabel } 6 & \text { Hul } \\
& \text { Pen }\end{array}$ & $\begin{array}{l}\text { ungan } \\
\text { ggunaan }\end{array}$ & ingkun & & engan \\
\hline \multirow{2}{*}{ Lingkungan } & \multicolumn{2}{|c|}{ Penggunaan APD } & \multirow{2}{*}{ Total } & \multirow{2}{*}{$\mathbf{p}$} \\
\hline & Buruk & Baik & & \\
\hline Buruk & 7 & 35 & 42 & \multirow{2}{*}{0,61} \\
\hline Baik & 8 & 30 & 38 & \\
\hline
\end{tabular}

Tabel 6 menunjukkan bahwa tidak ada hubungan antara lingkungan dan penggunaan APD dengan nilai $\mathrm{p}=0,61$

\begin{tabular}{|c|c|c|}
\hline $\begin{array}{l}\text { Hub } \\
\text { Peril }\end{array}$ & $\begin{array}{c}\text { Pengetahuan } \\
\text { nggunaan APD }\end{array}$ & dengan \\
\hline $\begin{array}{c}\text { Penggunaan } \\
\text { APD }\end{array}$ & Pengetahuan & $\mathbf{p}$ \\
\hline Buruk & 16 & \\
\hline Baik & 64 & 0,17 \\
\hline
\end{tabular}

Tabel 7 menunjukkan bahwa tidak ada hubungan antara pengetahuan dan perilaku penggunaan APD $(\mathrm{p}=0,17)$
Tabel 8 Hubungan Tingkat Pendidikan dengan Perilaku Penggunaan APD

\begin{tabular}{lcccc}
\hline \multirow{2}{*}{ Pendidikan } & \multicolumn{2}{c}{ Penggunaan APD } & \multirow{2}{*}{ Total } & p \\
\cline { 2 - 3 } & Buruk & Baik & & \\
\hline SMP & 1 & 6 & 7 & \\
SMA & 11 & 52 & 63 & 1.00 \\
Perguruan Tinggi & 1 & 4 & 5 & \\
Total & 13 & 62 & 75 & \\
\hline
\end{tabular}

Tabel 8 menunjukkan bahwa tidak ada hubungan antara tingkat pendidikan dan penggunaan APD $(\mathrm{p}=1,00)$.

Penelitian ini sudah mendapat persetujuan etik oleh Komite Etik Penelitian Kesehatan Fakultas Kedokteran Universitas Islam Bandung dengan nomor: 290/Komite Etik.FK/III/2018.

\section{Pembahasan}

Individu memiliki tingkat pengetahuan tinggi ketika mampu menjawab dengan benar rerata di atas $75 \%$. Hasil penelitian ini dapat dikatakan bahwa responden secara umum memiliki pengetahuan yang tinggi tentang penggunaan APD. ${ }^{5}$

Berdasar atas hasil uji analisis statistik pada 80 pegawai PT Sarandi Karya Nugraha Sukabumi dapat dinyatakan bahwa responden memiliki tingkat pengetahuan yang baik mengenai APD. Nilai rerata tingkat pengetahuan responden secara keseluruhan masuk ke dalam kategori tingkat pengetahuan tinggi.

Penelitian ini juga sejalan dengan penelitian Gurdani dan Indrisari ${ }^{6}$ mengenai tingkat pengetahuan APD yang menyatakan bahwa pada penelitiannya responden memiliki pengetahuan yang baik karena responden mendapatkan informasi yang baik mengenai kegunaan APD dan keuntungannya bila menggunakan APD.

Syarat dan ketentuan APD yang baik adalah yang dapat memberikan perlindungan terhadap bahaya, berbobot ringan, dapat dipakai secara fleksibel, tidak menimbulkan bahaya tambahan, tidak mudah rusak, memenuhi ketentuan standar yang ada, pemeliharaan murah, tidak membatasi gerak dan rasa "tidak nyaman" tidak berlebihan. ${ }^{1}$ Pada penelitian ini responden tidak banyak mengetahui mengenai syarat dan ketentuan APD dan hanya mengetahui jenis APD yang harus digunakan.

Pengetahuan responden yang tinggi dalam penelitian ini karena perusahaan telah memberikan pengarahan dan sosialisasi kepada setiap karyawan mengenai APD apa yang harus digunakan, namun tidak menjelaskan mengenai syarat dan ketentuan APD. Perusahaan juga memasang daftar APD yang harus digunakan di lokasi kerja, sehingga responden memiliki pengetahuan yang tinggi.

Di samping itu usia mendapatkan perhatian khusus karena akan memengaruhi kondisi fisik, mental, kemauan kerja, dan tanggung jawab seseorang. Teori psikologi perkembangan kerja menyatakan bahwa usia dapat digolongkan menjadi dewasa awal yaitu usia 18-40 tahun dan dewasa lanjut usia 41-6o tahun. 
Usia pekerja dewasa awal diyakini merupakan usia yang produktif untuk bekerja dan dapat membangun kesehatannya dengan mencegah suatu penyakit atau menanggulangi suatu penyakit.

Karakteristik usia dari responden juga dapat memengaruhi tingkat pengetahuan responden mengenai APD. Pada tahap dewasa awal kemampuan kognitif individu berada pada tahap yang prima karena individu mudah mempelajari, melakukan penalaran logis, berpikir kreatif, dan belum terjadi penurunan kesehatan. ${ }^{8}$ Hal ini juga sejalan dengan penelitian mengenai skor pengetahuan mengenai alat pelindung diri yang hasilnya adalah pengetahuan yang tinggi karena mayoritas usia responden penelitian ini adalah dewasa awal yang masih memiliki kemampuan kognitif yang baik. Pada penelitian ini, mayoritas responden adalah dalam usia dewasa muda dan berkaitan dengan teori psikologi perkembangan kerja yang menyatakan bahwa dewasa muda memiliki tingkat kognitif yang lebih baik.

Penetapan upah minimum kerja dilakukan di tingkat provinsi atau di tingkat kabupaten/kotamadya karena Gubernur menetapkan besaran upah minimum provinsi (UMP) atau upah minimum kerja (UMK). Dalam menetapkan kebijaksanaan berkenaan dengan masalah pemberian imbalan (penggajian) ada beberapa faktor yang harus diperhatikan oleh perusahaan. Faktor-faktor yang memengaruhi antara lain adalah karakteristik pekerja (prestasi, kinerja, loyalitas). ${ }^{9}$ UMK pada daerah perusahaan yang diteliti yakni Kabupaten Sukabumi adalah sebesar $2.583 .556,63$ rupiah. $^{10}$

Sosialisasi adalah proses belajar yang dialami seseorang untuk memperoleh pengetahuan ketrampilan, nilai-nilai, dan norma-norma agar ia dapat berpartisipasi sebagai anggota dalam kelompok masyarakatnya. Sosialisasi mengenai hal apapun dapat memberikan hasil berupa pengetahuan kepada seluruh pihak yang mendapatkan sosialisasi. ${ }^{11}$

Berdasar atas hasil hasil penelitian ini dapat dinyatakan bahwa tidak ada hubungan yang signifikan antara pendapatan dan penggunaan APD. Pendapatan dalam penelitian ini dikelompokkan menjadi kurang dari UMK, UMK, dan di atas UMK, namun tidak ada responden yang mendapatkan penghasilan kurang dari UMK. Dalam kelompok UMK dan di atas UMK memiliki perilaku penggunaan yang baik.

Mayoritas responden memiliki penghasilan sesuai dengan UMK dan menggunakan APD dengan baik. Hasil survei peneliti kepada responden di perusahaan terkait yang menunjukkan bahwa ada pembekalan atau sosialisasi mengenai APD kepada seluruh karyawan tidak memandang seberapa besar pendapatan dari karyawan sehingga dalam hal ini responden mayoritas menggunakan APD dengan baik. Bila dibanding dengan karyawan yang memiliki penghasilan sesuai dengan UMK adalah pegawai dengan usia dewasa muda sehingga lebih baik dalam menerapkan informasi-informasi yang didapat tentang penggunaan APD karena memiliki kognitif yang lebih baik. Tidak ada hubungan dalam penelitian ini juga kemungkinan karena jumlah sampel yang sedikit.

Sikap di sini dibagi menjadi 2 kelompok, yaitu positif (merasa senang/mendukung) dan negatif (tidak merasa senang/tidak mendukung).

$\mathrm{Hal}$ ini sama dengan penelitian $\mathrm{Nita}^{12}$ Insani mengenai analisis kepatuhan pekerja terhadap penggunaan alat pelindung diri di PT X dalam penelitian tersebut juga diyatakan bahwa tidak ada hubungan antara sikap dan perilaku penggunaan APD. Pada penelitian ini juga dapat disimpulkan bahwa tidak ada hubungan antara sikap dan penggunaan APD. Berdasar atas data diketahui bahwa meskipun memiliki sikap positif terhadap penggunaan APD tidak menjamin akan mempraktikkan pengunaan APD saat bekerja.

Penelitian ini juga sejalan dengan penelitian Indri $\mathrm{dkk}^{13}$ yang menyatakan bahwa karena sikap merupakan suatu reaksi menerima atau menolak pesan informasi yang diterima oleh akal maka jika informasi yang diterima tersebut dipahami maka belum tentu informasi tersebut dilaksanakan. Orang yang memiliki sikap positif belum tentu menggunakan APD dengan baik karena ada faktor lain, yaitu ketidaknyamanan dalam menggunakan APD itu sendiri. ${ }^{13}$

Penelitian Gurdani dan Indrisari ${ }^{6}$ mengenai sikap terhadap perilaku penggunaan APD juga menunjukkan tidak ada korelasi yang signifikan antara sikap dan perilaku penggunaan APD. Penelitian ini menyatakan bahwa sikap sendiri merupakan faktor pemungkin untuk terjadi suatu perilaku karena sifat masih merupakan respons yang tertutup terhadap objek atau stimulus. Manifestasi dalam sikap ada yang tidak terlihat yang disebut dengan covert behavior dan yang terlihat, yaitu overt behavior.

Penelitian lain menyatakan terdapat hubungan antara sikap dan perilaku penggunaan APD, yaitu penelitian Widyaningsih ${ }^{14}$ mengenai faktor predisposisi dengan implementasi penggunaan APD didapatkan nilai $\mathrm{p}=0,03$. Menurutnya sikap yang positif yang mendapat dukungan sosial dan tersedianya fasilitas akan memengaruhi tindakan atau praktik seseorang. Sikap positif dalam upaya pencegahan kecelakaan kerja dan penyakit akibat kerja merupakan motivasi untuk pemakaian APD saat bekerja.

Tidak ada hubungan antara sikap dan perilaku penggunaan APD pada penelitian ini dapat terjadi karena banyak pekerja mengeluhkan tidak nyaman menggunakan APD.

Lingkungan kerja merupakan salah satu komponen terpenting untuk karyawan menyelesaikan pekerjaannya. Di sini yang dimaksud dengan lingkungan kerja adalah segala sesuatu yang ada di sekitar para pekerja yang dapat memengaruhi dirinya dalam menjalankan tugas-tugas yang dibebankan. Lingkungan kerja ada dua macam, yaitu lingkungan kerja fisik dan lingkungan kerja nonfisik. Lingkungan kerja fisik adalah semua keadaan berbentuk fisik yang terdapat di sekitar tempat kerja yang dapat memengaruhi karyawan baik secara langsung maupun tidak langsung, sedangkan lingkungan kerja nonfisik adalah semua keadaan yang terjadi yang berkaitan dengan hubungan kerja, baik hubungan kerja dengan atasan maupun hubungan sesama rekan kerja, ataupun hubungan dengan bawahan. ${ }^{15}$

Menurut penelitian Baihaqi ${ }^{16}$ tahun 2009 menyatakan bahwa secara analisis statistik tidak ada perbedaan atau hubungan bermakna antara 
lingkungan dan kepatuhan penggunaan APD.

Hasil penelitian ini didapatkan $\mathrm{p}=0,61$ sehingga dapat disimpulkan tidak ada hubungan antara lingkungan dan penggunaan APD. Kesamaan dengan penelitian Baihaqi adalah kemungkinan adanya kesadaran yang kurang mengenai kesehatan kerja. Kemungkinan lain adalah pemberlakuan sanksi kurang kepada karyawan yang tidak menggunakan APD.

Penelitian dari Eltha $^{17}$ menyatakan bahwa tidak terdapat hubungan yang signifikan antara pengetahuan dan perilaku penggunaan APD. Tidak terdapat hubungan dalam penelitian Eltha karena pada perusahaan tidak ditetapkan aturan yang baik mengenai penggunaan APD sehingga pegawai hanya sebatas pada tingkatan tahu.

Penelitian ini juga sejalan dengan penelitian Liswanti ${ }^{18}$ mengenai tingkat pengetahuan terhadap penggunaan APD di STIKES Tasikmalaya yang didapatkan niali $\mathrm{p}>0,05$. Tidak ada hubungannya dalam penelitian ini dikarenakan responden hanya sekedar mengetahui mengenai APD, namun tidak mengaplikasikan dalam bentuk tindakan.

Hal ini sesuai teori Bloom yang menyatakan bahwa domain pengetahuan berawal dari tahu hingga domain aplikasi. Domain tahu hanya mengetahui tentang prinsip-prinsip APD, namun belum dapat menerapkannya dalam perilaku ketika praktik. Responden juga memerlukan peralatan penunjang, yaitu peralatan APD di tempat kerja untuk dapat menggunakan. Meskipun responden memiliki pengetahuan yang tinggi jika tidak didukung dengan ketersediaaan APD di tempat kerja maka responden tidak dapat menggunakan APD dengan baik. ${ }^{18}$

Penelitian lain yaitu penelitian Adriansyah ${ }^{19}$ mengenai pengetahuan dan perilaku penggunaan APD menunjukkan ada hubungan tingkat pengetahuan APD dan $\mathrm{K}_{3}$ dengan perilaku penggunaan APD karena responden telah mempunyai 6 domain pengetahuan.

Hasil penelitian yang dilakukan pada 80 responden menunjukkan bahwa responden memiliki tingkat pengetahuan yang tinggi (benar di atas $75 \%)$ tentang APD. Namun, didapatkan hasil nilai $\mathrm{p}$ $>0,05$ maka dalam penelitian ini dapat disimpulkan tidak terdapat hubungan antara pengetahuan dan perilaku penggunaan APD. Kemungkinan tidak ada hubungannya pada penelitian ini adalah karena kurang aturan yang baik dari perusahaan dan hanya memberikan teguran kepada karyawan sehingga masih banyak karyawan yang paham mengenai APD, tetapi tidak merealisasikannya dalam bentuk suatu tindakan. Selain itu, diperlukannya jumlah APD yang memadai agar karyawan dapat menggunakannya dengan baik dan benar.

Hubungan tingkat pendidikan dengan perilaku penggunaan alat pelindung diri, pendidikan adalah jenjang pendidikan formal yang pernah diikuti oleh seseorang. Konsep dasar pendidikan adalah suatu proses belajar yang berarti di dalam pendidikan itu terjadi pertumbuhan, perkembangan, atau perubahan ke arah yang lebih dewasa, lebih baik, dan lebih matang pada diri individu, kelompok, atau masyarakat. ${ }^{20}$

Menurut penelitian lain menyatakan tingkat pendidikan sangat berpengaruh terhadap pengetahuan pekerja dan membentuk perilaku secara langsung maupun tidak langsung. Oleh karena itu, meskipun dalam perusahaan terdapat pekerjayang berpendidikan rendah, perusahaan dapat meminimalisir dampak dari perilaku pekerja yang berpendidikan rendah dengan memberikan sosialisasi terkait APD untuk menumbuhkan betapa pentingnya menggunakan APD saat bekerja. ${ }^{21}$

Penelitian ini juga sejalan dengan penelitian Wekoyla $^{20}$ mengenai hubungan tingkat pendidikan terhdap perilaku penggunaan APD di Rumah Sakit Umum Kota Kendari dan didapatkan hasil p >0,05 sehingga dapat disimpulkan tidak ada hubungan antara tangkat pendidikan dan penggunaan APD. Tidak ada hubungan dalam penelitian Wekoyla ini karena rumah sakit menerapkan sistem pembelajaran kepada semua karyawan cara menggunakan APD dan mengubah pola pikir karyawan mengenai APD. ${ }^{20}$

Pada penelitian ini didapatkan nilai $\mathrm{p}=1,00$ sehingga dapat disimpulkan tidak ada hubungan antara tingkat pendidikan dan penggunaan APD. Hal ini disebabkan karena berdasar hasil survei, perusahaan melakukan sosialisasi mengenai APD kepada seluruh karyawan tanpa memandang tingkat pendidikan.

Perusahaan menetapkan sanksi yang lebih tegas kepada pekerja yang tidak mematuhi peraturan penggunaan APD. Karyawan selalu menggunakan APD saat bekerja untuk menurunkan risiko kecelakaan kerja dan penyakit akibat kerja.

\section{Simpulan}

Tidak terdapat hubungan antara pengetahuan dan perilaku penggunaan alat pelindung diri di PT Sarandi Karya Nugraha Sukabumi. Tidak terdapat hubungan antara sikap dan perilaku penggunaan alat pelindung diri di PT Sarandi Karya Nugraha Sukabumi.

\section{Ucapan Terima Kasih}

Ucapan terima kasih dan juga penghargaan penulis sampaikan kepada PT Sarandi Karya Nugraha Sukabumi dan responden yang telah bersedia mengikuti penelitian ini.

\section{Daftar Pustaka}

1. Sugeng Budiono AM, Yusuf RMS, Pusparini A. Bunga rampai hiperkes \& kk. Semarang: Universitas Diponegoro Semarang; 2013.

2. Kementrian Kesehatan Republik Indonesia 2014. 1 orang pekerja di dunia meninggal setiap 15 detik karena kecelakaan kerja. 2014 okt 28. [diunduh Januari 2018]. Tersedia dari: http://www.depkes. go.id/article.html

3. Direktorat Kesehatan Kerja \& OlahragaKementrian Kesehatan RI [diunduh 23 Januari 2018]. Tersedia dari: http://www.kesjaor. kemenkes.go.id

4. Peraturan Menteri Tenaga Kerja dan Transmigrasi Republik Indonesia [diunduh 25 januari 2018]. Tersedia dari: http://www.gmf-aeroasia.co.id

5. Sunaryo M. Psikologi untuk keperawatan. Dalam: 
Monica Ester, penyunting. Edisi ke-1. Jakarta: Penerbit Buku Kedokteran ECG; 2004.

6. Gurdani Y. Indrisari C. The relationship between knowledge and attitude of worker's in using personal protective equipment in departement of forging and casting of metal company in Bandung [diunduh Agustus 2018]. Tersedia dari: https:// www.researchgate.net/publication/225284815

7. Saputro VA. Hubungan antara pengetahuan dan sikap dengan penggunaan alat pelindung diri (APD) pada pekerja di unit kerja produksi pengecoran logam (skripsi). Surakarta: Universitas Muhammadiyah Surakarta; 2015. [diunduh 12 Juli 2018]. Tersedia dari: http:// eprints.ums.ac.id/38480/1/02

8. Nitisemito. Lingkungan kerja. Dalam: Nuraini T. Manajemen sumber daya manusia. Pekanbaru: Yayasan Aini Syam; 2013.

9. Kebijakan upah minimum Indonesia. [diunduh Juli 2018]. Tersedia dari: http://www.ilo.org

10. Pergub Jawa Barat. Keputusan Gubernur Jawa Barat Nomor 561 Tahun 2017 tentang UMK Provinsi Jawa Barat 2018. 2018:5. [diunduh Agustus 2018]

11. Andri S. Komunikasi dan sosialisasi dalam masyarakat. [diunduh Agustus 2018]. Tersedia dari: https://www.google.com/ search?q=andri+s+komunikasi

12. Saragih VI, Kurniawan B, Ekawati E. Analisis kepatuhan pekerja terhadap penggunaan alat pelindung diri (Apd) (studi kasus area produksi di PT X). JKM Universitas Diponegoro. 2016 Okt;4(4):747-55.

13. Indri S. Yasnani. Sabril M. Faktor yang berhubungan dengan perilaku penggunaan alat pelindung diri pada tenaga teknisi PT PLN Sulselbar Sektor pembangkitan Kendari unit PLTD Wua-Wua kota Kendari. J Ilm Kes Masy. 2018;2(6):250.
14. Widyaningsih. Hubungan faktor predisposisi dengan implementasi pemakaian alat pelindung diri pada tenaga kerja di PT Suwastama Pabelan Kartasura. [diunduh Juli 2018]. Surakarta: F Kedokteran UNS: 2012.

15. Rahmawati NP. Pengaruh lingkungan kerja terhadap kinerja karyawan (studi pada karyawan kantor pelayanan pajak Pertama Malang Utara). J Administrasi Bisnis. 2014;8(2).

16. Baihaqi I. Hubungan pengetahuan dan sikap dengan perilaku penggunaan alat pelindung diri. 2009. [diunduh Juli 2018]. Tersedia dari: http:// lib.ui.ac.id

17. Ginting EA. Faktor-faktor yang berhubungan denganperilakupenggunaanAPDpadakaryawandi bagian pengolahan PTPN II Tanjung Garbus 2017. [diunduh juli 2018]. Tersedia dari: https://www. semanticscholar.org/paper/Faktor-Faktor-YangBerhubungan-Dengan-Perilaku-Alat-Ginting/ bdocae5e6818f83878e851a3990d626cb37dc5e5

18. Liswanti Y. Hubungan tingkat pengetahuan dengan perilaku penggunaan alat pelindung diri pada mahasiswa prodi DIII analisis kesehatan STIKES BTH Tasikmalaya. J Kes Bakti Tunas Husada. 2017 Agustus;12(2) [diunduh 6 Juli 2018].

19. Adriansah. Hubungan tingkat pengetahuan $\mathrm{K}_{3}$ dengan sikap terhadap pemakaian APD pada pekerja di sentra industri pandebesi desa pedas kabupaten Klaten.[diunduh Juli 2018]. Tersedia dari: http://eprints.ums.ac.id

20. Wekoyla. Hubungan pengetahuan, sikap, pendidikan dan masa kerja bidan terhadap perilaku penggunaan APD di RSU Sulawesi Tenggara dan Kota Kendari 2012 [diunduh 4 Juli 2018]. Tersedia dari: http://lib.ui.ac.id

21. Maulana MIS. Gambaran faktor perilaku penggunaan APD pada pekerja metalforming PT. Dirgantara Indonesia (Persero). 2014 [diunduh 3 juli 2018]. Tersedia dari: https://onesearch.id/ record/1053659.81504/TOC 